\title{
Motivasi dan tanggung jawab siswa dalam pembelajaran berbasis proyek, sebuah penelitian tindakan kelas
}

\author{
Rr. Eko Susetyarini ${ }^{1}$, Tutut Indria Permana ${ }^{1}{ }^{*}$, Gunarta Gunarta ${ }^{2}$, Dwi Setyawan ${ }^{1}$, Roimil \\ Latifa $^{1}$, Siti Zaenab ${ }^{1}$ \\ ${ }^{1}$ Program Studi Pendidikan Biologi, Fakultas Keguruan dan Ilmu Pendidikan, Universitas \\ Muhammadyah Malang. Jalan Raya Tlogomas 246, Kota Malang, Jawa Timur 65144, Indonesia \\ ${ }^{2}$ SMA Negeri 4 Malang. Jalan Tugu No.1, Klojen, Kota Malang, 65111, Indonesia \\ * Coressponding Author. E-mail: tutut.indria@umm.ac.id
}

Received: 8 December 2018; Revised: 28 March 2019; Accepted: 11 April 2019

\begin{abstract}
Abstrak
Perkembangan teknologi di era revolusi industri 4.0 memberikan tantangan kepada siswa agar mampu menghadapi berbagai macam situasi. Siswa sebagai generasi muda yang akan hidup di era tersebut harus memiliki motivasi belajar dan rasa tanggung jawab yang tinggi. Motivasi siswa akan muncul ketika mereka dihadapkan pada tugas proyek yang harus diselesaikan dalam waktu tertentu, sama halnya dengan rasa tanggung jawab mereka. Oleh karena itu penelitian ini bertujuan untuk meningkatkan motivasi dan rasa tanggung jawab siswa dalam pembelajaran berbasis proyek. Penelitian tindakan kelas ini menggunakan 34 siswa Sekolah Menengah Atas (SMA) sebagai subjek penelitian. Motivasi dan rasa tanggung jawab siswa diukur dengan menggunakan lembar observasi dan kuesioner. Data hasil observasi dan kuesioner dianalisis menggunakan perhitungan persentase. Hasil penelitian menunjukkan bahwa ada peningkatan motivasi dan rasa tanggung jawab siswa setelah implementasi pembelajaran berbasis proyek.
\end{abstract}

Kata Kunci: motivasi siswa, pembelajaran berbasis proyek, tanggung jawab siswa

\section{Students' motivation and responsibility in project-based learning, a classroom action research}

\begin{abstract}
Technological developments in the industrial revolution era 4.0 provide a challenge for students to be able to face a variety of situations. Student, as gold generation, must have the motivation to learn and a high sense of responsibility. Motivation of students will emerge when they are faced with project tasks that must be completed in a certain time, as well as their sense of responsibility. Therefor this study aims to improve students' motivation and their sense of responsibility describe in project-based learning. This qualitative descriptive study uses 34 senior high school students as the research subjects. Motivation and students' responsibility is measured using an observation sheet and questionnaire. The data obtained was analyzing using percentage. The results showed that there was an improvement in students' motivation and sense of responsibility after the implementation of project-based learning.
\end{abstract}

Keywords: students' motivation, students' responsibility, project-based learning, action research

How to Cite: Susetyarini, R., Permana, T., Gunarta, G., Setyawan, D., Latifa, R., \& Zaenab, S. (2019). Motivasi dan tanggung jawab siswa dalam pembelajaran berbasis proyek, sebuah penelitian tindakan kelas. Jurnal Inovasi Pendidikan IPA, 5(1), 1-9. doi:https://doi.org/10.21831/jipi.v5i1.22293

https://doi.org/10.21831/jipi.v5i1.22293

\section{PENDAHULUAN}

Perkembangan teknologi di era revolusi industri 4.0 memberikan tantangan kepada siswa agar mampu menghadapi berbagai macam keadaan (Aulbur, CJ, \& Bigghe, 2016; Hartmann \& Bovenschulte, 2013; Pfeiffer, 2015). Siswa sebagai generasi muda yang akan hidup di era tersebut harus memiliki motivasi belajar yang tinggi. Memberikan atau menumbuhkan motivasi siswa adalah salah satu aspek yang paling sulit bagi seorang guru (2U Inc., 2018; Lubis et al., 2011; Puspitorini, Prodjosantoso, Subali, \& Jumadi, 2014; Ratnaningrum, Chamisijatin, \& 
Widodo, 2016; Saragih, 2012; Taufik, 2014; Yulistiana, 2010).

Motivasi berkaitan erat dengan keyakinan, persepsi, nilai, minat, dan tindakan. Akibatnya, berbagai pendekatan untuk motivasi dapat fokus pada kognitif, aspek non-kognitif (seperti persepsi, keyakinan, dan sikap), atau keduanya (Lai, 2011). Gottfried (1990) mendefinisikan motivasi akademik sebagai kesenangan belajar di sekolah yang ditandai dengan orientasi penguasaan, keingintahuan, ketekunan, dan mempelajari tugas yang menantang, sulit, dan baru. Di sisi lain, Turner (1995) menganggap motivasi sebagai penggunaan strategi pembelajaran tingkat tinggi pada diri sendiri, seperti memperhatikan, membuat hubungan, merencanakan, dan melakukan pemantauan.

Siswa yang tidak termotivasi tidak akan belajar secara efektif. Mereka tidak akan menyimpan informasi, mereka tidak akan berpartisipasi dan beberapa dari mereka bahkan mungkin menjadi pengganggu temannya (2U Inc., 2018; Irvin, Meltzer, \& Dukes, 2007). Siswa yang tidak termotivasi bisa disebabkan oleh berbagai alasan, seperti mereka tidak tertarik pada subjek, metode guru yang ti-dak menarik atau terganggu oleh faktor eksternal. Bahkan dapat terungkap bahwa seorang siswa yang tampak tidak termotivasi sebenarnya meng-alami kesulitan belajar dan membutuhkan per-hatian khusus (2U Inc., 2018).

Sebaliknya, siswa yang termotivasi lebih bersemangat untuk belajar dan berpartisipasi. Secara sederhana, mengajar kelas yang penuh dengan siswa yang termotivasi akan menciptakapan suasana menyenangkan bagi guru dan murid ( $2 \mathrm{U}$ Inc., 2018; Filak \& Sheldon, 2008; Irvin et al., 2007; Saeed \& Zyngier, 2012; Taurina, 2015). Beberapa siswa memiliki motivasi dari dalam dirinya sendiri, karena mereka suka bel-ajar. Tetapi bagi para siswa yang tidak memiliki motivasi diri maka membutuhkan seorang guru yang dapat membuat belajar menjadi menyenangkan dan menginspirasi mereka untuk mencapai kompetensi mereka. Siswa yang bermotivasi tinggi akan bertahan pada tugas yang bahkan sulit atau menantang, sedangkan siswa dengan motivasi rendah akan cenderung mengurangi upaya atau keterlibatan mereka dengan tugas ketika disajikan dengan tantangan yang lebih (Turner, 1995).

Selain motivasi belajar yang baik, siswa juga perlu mengembangkan rasa tanggung jawab (D. Patrick Saxon, 2013; Erb, 1996; Jati, 2016; Swain, 2012). Tanggung jawab personal sebagai prinsip fundamental yang mendasari berbagai upaya individu dan interaksi sosial, termasuk pendidikan formal dan pembelajaran (CookSather, 2010; Erb, 1996; Swain, 2012). Menurut beberapa psikolog, tanggung jawab personal juga dikaitkan dengan individu yang mampu mengendalikan pikiran, tindakan, dan keinginan pribadi mereka (Bandura, 1991). Dengan demikian siswa yang memiliki rasa tanggung jawab akan mampu mengatur dan menentukan prioritas mereka dan tingkah laku mereka dalam pembelajaran, bahkan sepanjang hidup mereka setelah masuk ke dalam masyarakat.

Rasa tanggung jawab siswa akan muncul ketika mereka dihadapkan pada tugas proyek yang harus diselesaikan dalam waktu tertentu, seperti pada pembelajaran berbasis proyek (Baker, Trygg, Otto, Tudor, \& Ferguson, 2011; Bell, 2010; Dean et al., 2001; Schwartz, Tessman, \& Mcdonald, 2013; Takeda, 2016). Pembelajaran berbasis proyek berkaitan dengan pembelajaran yang mengajarkan banyak strategi penting untuk sukses di era revolusi industry saat ini (Bell, 2010). Siswa terdorong untuk melakukan pembelajaran mereka sendiri melalui inkuiri, serta bekerja secara kolaboratif untuk meneliti dan membuat proyek yang mencerminkan pengetahuan mereka (Arce, Miguez, Granada, Miguez, \& Cacabelos, 2013; Badia \& Soria, 2017; Baker et al., 2011; Bell, 2010; Isabekov \& Sadyrova, 2018). Dengan penerapan pembelajaran berbasis proyek, siswa dilatih untuk bisa mengkomunikasikan pendapatnya dengan mahir dan menjadi pemecah masalah yang handal (Bell, 2010; Chiang \& Lee, 2016). Kemampuan siswa ini akan sejalan dengan meingkatnya rasa tanggungjawab mereka dalam belajar maupun menyelesaikan permasalahan.

Tidak hanya rasa tanggungjawab siswa, tetapi siswa juga akan lebih termotivasi dalam proses pembelajaran. Beberapa penelitian menunjukkan bahwa siswa lebih bersemangat dalam belajar ketika mereka melakukan suatu proyek (Badia \& Soria, 2017; Bell, 2010; Ergül \& Kargin, 2014; Lin \& Wu, 2016). Oleh karena itu penelitian ini bertujuan untuk mendiskripsikan bagaimana pembelajaran berbasis proyek dapat meningkatkan motivasi dan rasa tanggung jawab siswa dalam pembelajaran.

\section{METODE}

Penelitian ini merupakan penelitian tindakan kelas yang dilakukan di Sekolah Menengah Atas (SMA) Negeri 4 Malang. Penelitian dilakukan selama bulan Juli-Agustus 2018 dengan 34 siswa kelas XI IPA 1 sebagai subjek 
Jurnal Inovasi Pendidikan IPA, 5 (1), 2019 - 3

Rr. Eko Susetyarini, Tutut Indria Permana, G. Gunarta, Dwi Setyawan, Roimil Latifa, Siti Zaenab

penelitian. Jadwal kegiatan penelitian ini tercantum dalam Tabel 1, yang menunjukkan bahwa kegiatan penelitian tindakan kelas dilakukan selama dua siklus yang terdiri dari kegiatan perencanaan, pelaksanaan dan refleksi. Kegiatan observasi dilakukan di awal sebelum pembelajaran siklus I dilakukan, yaitu pada pertengahan bulan Agustus 2018. Materi pembelajaran yang dipilih adalah "struktur dan jaringan tumbuhan" pada siklus I dan "organ tumbuhan: bunga" pada siklus berikutnya.

Tabel 1. Jadwal Kegiatan Penelitian pada

Pembelajaran Berbasis Proyek di SMAN 4 Malang

\begin{tabular}{clc}
\hline No. & Kegiatan & Tanggal \\
\hline 1. & Observasi & $18 / 07 / 2018$ \\
2. & Perencanaan I & $4 / 08 / 2018$ \\
3. & Pelaksanaan I & $6 / 08 / 2018 \& 8 / 08 / 2018$ \\
4. & Refleksi I & $8 / 08 / 2018$ \\
5. & Perencanaan II & $11 / 08 / 2018$ \\
6. & Pelaksanaan II & $13 / 08 / 2018 \& 15 / 08 / 2018$ \\
7. & Refleksi II & $15 / 08 / 2018$ \\
\hline
\end{tabular}

Tabel 2. Aspek Motivasi dan Indikatornya

\begin{tabular}{|c|c|c|}
\hline No. & Aspek & Indikator \\
\hline 1. & $\begin{array}{l}\text { Penggunaan } \\
\text { strategi yang } \\
\text { efektif }\end{array}$ & $\begin{array}{l}\text { - Melakukan elaborasi } \\
\text { - Mengorganisasi } \\
\text { - Memahami bacaan }\end{array}$ \\
\hline 2. & Ketekunan & $\begin{array}{l}\text { - Meminta bantuan } \\
\text { - Menanyakan } \\
\text { pertanyaan pada diri } \\
\text { sendiri }\end{array}$ \\
\hline 3. & Kemauan & $\begin{array}{l}\text { - Mengajukan pendapat } \\
\text { secara spontan } \\
\text { - Meminta orang lain } \\
\text { untuk tidak } \\
\text { mengganggu } \\
\text { - Mengubah tingkat } \\
\text { tantangan tugas agar } \\
\text { lebih mudah }\end{array}$ \\
\hline
\end{tabular}

Motivasi siswa diamati menggunakan lembar observasi berdasarkan tiga aspek (Turner, 1995) yang disajikan pada Tabel 2. Sedangkan tanggung jawab siswa diamati menggunakan pernyataan kuesioner yang dikembangkan oleh peneliti. Hasil observasi dan kuesioner selanjutnya dianalisis menggunakan perhitungan nilai persentase dan dianalisis secara deskriptif dengan menunjukkan bukti-bukti autentik saat observasi ketika pembelajaran berlangsung.

\section{HASIL DAN PEMBAHASAN}

Hasil penelitian dijelaskan secara deskriptif mulai dari observasi, pelaksanaan siklus I dan pelaksanaan siklus II.

\section{Observasi}

Observasi dilakukan pada tanggal 18 Juli 2018 dengan materi pembelajaran tentang sejarah penemuan sel dan komponen kimiawi di dalam sel. Hasil temuan pada observasi pembelajaran di kelas XI IPA 1 menunjukkan bahwa: Pertama, pembelajaran dilakukan dengan diskusi kelompok dan menggunakan Lembar Kerja Belajar Mandiri (LKBM) seperti pada Gambar 1. Siswa sebelumnya diberikan tugas untuk mempelajari LKBM di rumah. Selanjutnya dilakukan diskusi dalam kelas berdasarkan hasil kerja individu. Namun $80 \%$ dari 34 siswa belum mengerjakan LKBM tersebut. Seperti yang terlihat pada Gambar 1 menunjukkan siswa laki-laki yang mengerjakan LKBM di kelas.

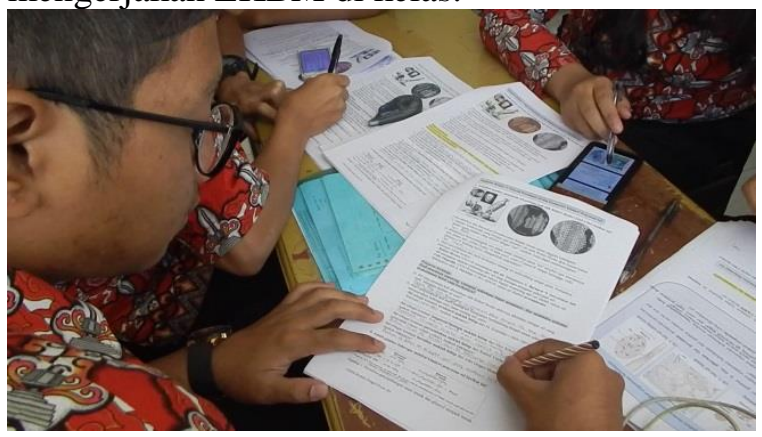

Gambar 1. LKBM yang Digunakan oleh Siswa untuk Diskusi dalam Kelas

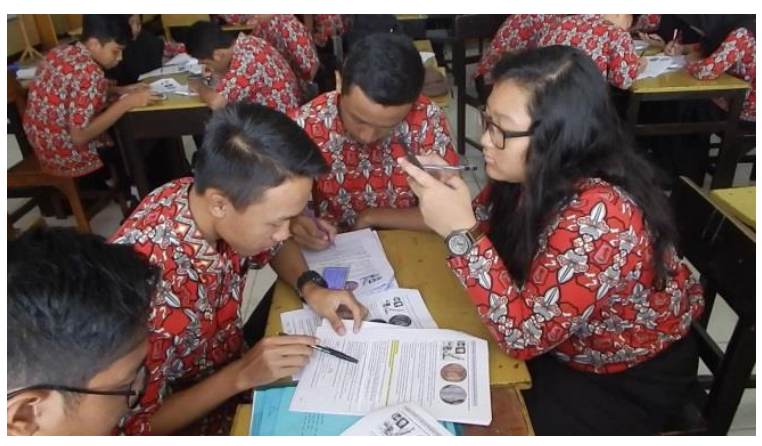

Gambar 2. Pembagian Kelompok Siswa yang tidak Heterogen, Satu Kelompok 3 Siswa LakiLaki dan 1 Perempuan

Kedua, kelompok diskusi siswa dibentuk secara insidental, sehingga tidak heterogen seperti pada Gambar 2. Gambar 2 menunjukkan bahwa ada kelompok yang beranggotakan tiga anak laki-laki dan satu anak perempuan. Ini menunjukkan pembentukan kelompok tidak heterogen.

Ketiga, terdapat siswa yang kurang termotivasi ketika guru memberikan penguatan. Gambar 3 menunjukkan seorang siswa laki-laki di kelompok yang duduk di belakang menyandar- 
kan kepala di atas tangan ketika guru memberikan penjelasan.

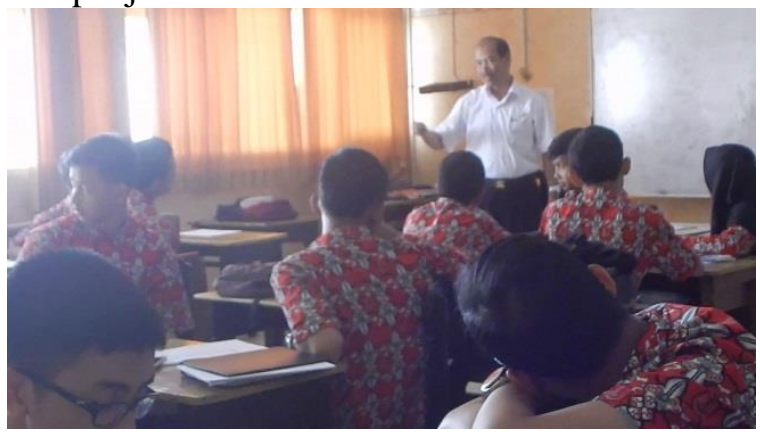

Gambar 3. Siswa yang Kurang Termotivasi Selama Proses Diskusi

Keempat, Siswa mengemukakan pendapatnya berdasarkan hasil diskusi kelompok di akhir pembelajaran seperti pada Gambar 4. Selanjutnya guru akan memberikan penguatan materi pada siswa.

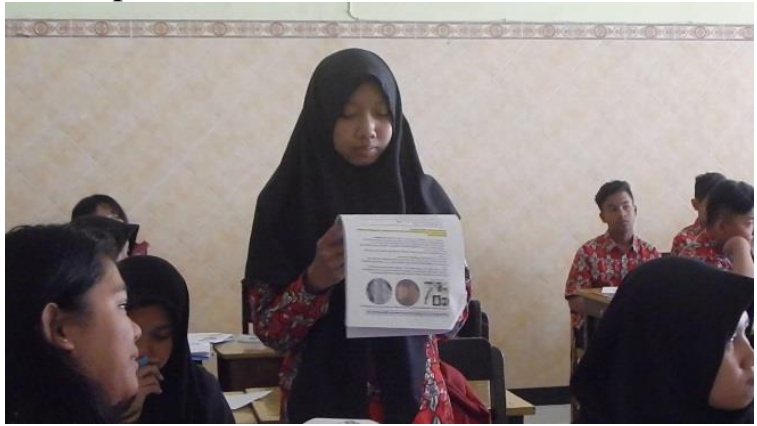

Gambar 4. Siswa Mempresentasikan Hasil Diskusinya

Berdasarkan temuan tersebut, dketahui bahwa proses pembelajaran siswa terpusat pada LKBM sehingga siswa kurang termotivasi dalam belajar. Selain itu rasa tanggung jawab siswa masih kurang terakomodasi di dalam pembelajaran. Hal ini terbukti dari hasil observasi yang menunjukkan bahwa siswa tidak menyelesaikan LKBM diluar jam pelajaran, melainkan mulai mengerjakannya saat diskusi kelompok.

\section{Siklus I}

\section{Perencenaan I}

Tahap perencanaan pada siklus I dilakukan dengan mempertimbangkan temuan yang didapat pada kegiatan observasi. Motivasi dan tanggung jawab siswa yang rendah perlu ditingkatkan dengan implementasi pembelajaran berbasis proyek. Materi pokok yang digunakan adalah "Penyusun Jaringan Tumbuhan". Kegiatan perencanaan diikuti oleh guru SMAN 4 Malang dan tim dosen Universitas Muhammadiyah Malang (UMM), seperti yang disajikan pada
Gambar 5. Pembelajaran yang akan dilakukan yaitu siswa akan menentukan bahan yang sesuai untuk membuat model jaringan penyusun tumbuhan. Siswa diberikan kebebasan untuk bereksplorasi secara kelompok untuk menentukan bahan dan desain dari model yang akan dibuat.

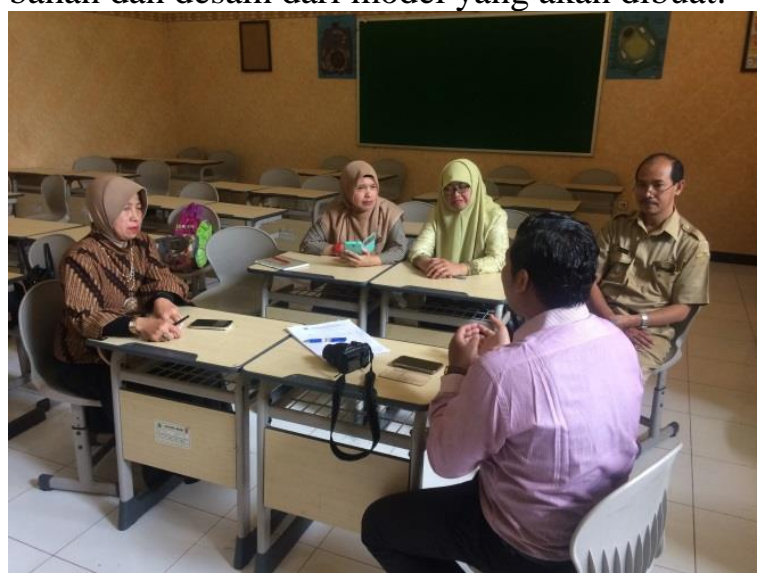

Gambar 5. Kegiatan Perencanaan Siklus I

Sebagai upaya untuk membuat siswa termotivasi dan memiliki rasa tanggung jawab dalam proses pembelajaran, siswa melakukan seminar kelompok untuk mempresentasikan hasil kerja proyek mereka. Setiap kelompok akan dibagi menjadi dua kelompok kecil, kelompok pertama bertugas untuk memberikan penjelasan terkait model jaringan tumbuhan yang dibuat, sedangkan kelompok kedua bertugas untuk keliling ke kelompok lain untuk memperoleh penjelasan model jaringan tumbuhan dari kelompok lain. Selanjutnya setelah proses keliling selesai, kelompok kedua akan berbagi ilmu (sharing learning) yang diperoleh dari kelompok lain.

\section{Pelaksanaan I}

Tahap ini dilakukan dalam dua pertemuan, yaitu hari Senin 6 Agustus 2018 (pertemuan pertama) dan Rabu 8 Agustus 2018 (pertemuan kedua). Sebagai apresepsi, guru meanyangkan video terkait kesulitan yang dialami seeorang ketika belajar jaringan tumbuhan. Siswa diarahkan untuk membuat model jaringan penyusun tumbuhan sebagai alternatif solusi dari permasalahan tersebut. Hal ini dilakukan untuk menumbuhkan motivasi dari siswa melalui video permasalahan (Vrbik \& Vrbik, 2017; Williams \& Williams, 2011). Selanjutnya siswa berdiskusi dengan kelompok yang sudah dibuat oleh guru secara heterogen.

Pada pertemuan pertama ini siswa mendiskusikan bahan dan desain untuk tugas proyek mereka (Gambar 6). Setiap kelompok membuat 
jaringan tumbuhan yang berbeda sesuai dengan hasil undian. Selanjutnya setiap kelompok mempresentasikan hasil desainnya untuk mendapatkan saran dari kelompok lain dan juga guru. Model jaringan tumbuhan sebagai tugas proyek dikerjakan di luar jam pelajaran dan dipresentasikan pada pertemuan kedua.

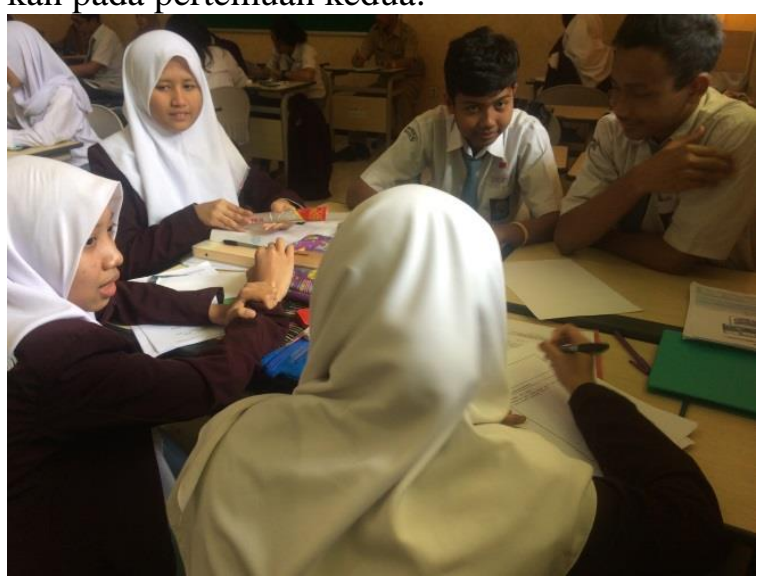

Gambar 6. Siswa Berdiskusi untuk Menentukan Desain Model Jaringan Penyusun Tumbuhan

Beserta Bahan-Bahan yang Diperlukan

Pada pertemuan kedua, siswa mempresentasikan hasil proyek mereka dalam bentuk seminar. Model jaringan tumbuhan yang disusun oleh siswa sangat beragam denganberbagai macam bahan. Masing-masing kelompok bertanggung jawab atas model jaringan tumbuhan yang dibuat, seperti pada Gambar 7.

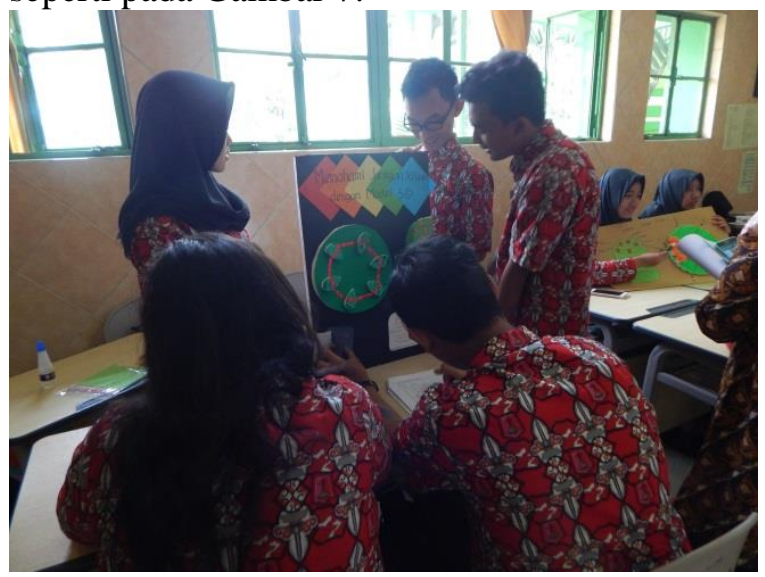

Gambar 7. Kegiatan Seminar Kelompok yang Dilakukan Siswa untuk Mempresentasikan Hasil Proyek

Pada kegiatan presentasi produk ini ada juga kelompok siswa yang menggunakan video untuk membantu menjelaskan materi terkait tugas proyek mereka. Hal ini menunjukkan bahwa siswa memiliki rasa tanggung jawab untuk memberikan penjelaskan materi kepada temannya sehingga mereka melakukan berbagai upaya untuk mendukung penjelasannya, termasuk menggunakan video. Selain itu, hal ini juga menunjukkan bahwa mereka sangat termotivasi dan antusias dalam belajar (Bell, 2010; Schwartz et al., 2013) tentang jaringan penyusun tumbuhan.

\section{Refleksi I}

Kegiatan refleksi siklus I dilakukan pada tanggal 8 Agustus 2018 (Gambar 8). Hasil refleksi pada pelaksanaan pembelajaran siklus I menunjukkan bahwa: Pertama, Banyak kelompok siswa yang belum menyelesaikan tugas proyeknya, sehingga guru perlu memberikan pemantauan di luar kelas, misalnya dengan membuat kelompok diskusi online. Hal ini menunjukkan bahwa tanggung jawab siswa terhadap tugasnya masih belum maksimal terbentuk.

Dengan menggunakan seminar kelompok untuk mempresentasian hasil proyek, guru belum menyampaikan materi penguatan. Dalam hal ini guru harus lebih bisa mengoptimalkan terbatasnya waktu pembelajaran di dalam kelas.

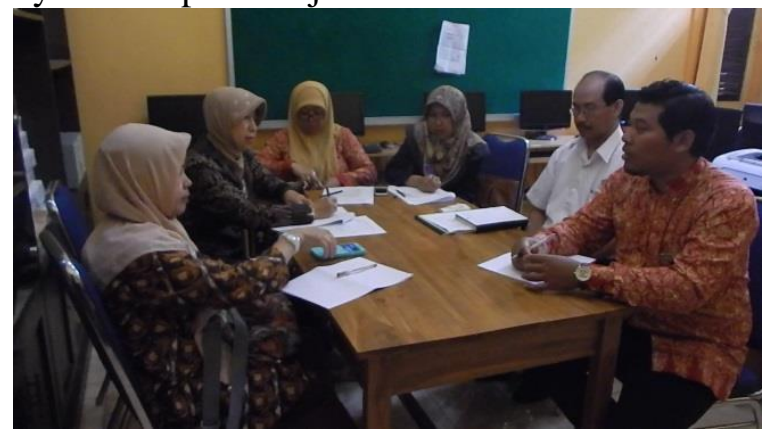

Gambar 8. Kegiatan Refeksi Siklus I

Berdasarkan hasil observasi, $70.59 \%$ dari 34 siswa menunjukkan motivasi mereka dalam proses pembelajaran berbasis proyek. Motivasi siswa muncul ketika ada tugas membuat proyek untuk belajar yang memaksa mereka untuk melakukan elaborasi, memahami bacaan dan bertanya pada teman lain. (Badia \& Soria, 2017; Bell, 2010; Ergül \& Kargın, 2014; Lin \& Wu, 2016; Turner, 1995). Sedangkan hasil kuesioner menunjukkan bahwa $58.82 \%$ dari 34 siswa yang sudah memiliki rasa tanggung jawab untuk belajar. Rendahnya tanggung jawab siswa dapat terjadi karena berbagai faktor (Turner, 1995), misalnya banyak kegiatan ektrakurikuler, kurang bisa mengelola waktu degan baik, dan kurang termotivasi dalam mengerjakan tugas (Taurina, 2015). 
Jurnal Inovasi Pendidikan IPA, 5 (1), 2019 - 6

Rr. Eko Susetyarini, Tutut Indria Permana, G. Gunarta, Dwi Setyawan, Roimil Latifa, Siti Zaenab

\section{Siklus II}

\section{Perencanaan II}

Tahap perencanan pada siklus II dilakukan dengan mempertimbangkan temuan yang didapat pada kegiatan refleksi siklus I. Hasil dari plan yang dilakukan yaitu tetap menerapkan pembelajaran berbasis proyek pada materi pokok "organ pada tumbuhan yaitu bunga" (Gambar 9). Namun pada kegiatan belajar siswa kali ini guru tidak meminta siswa untuk membuat model bunga, melainkan menyediakan media realia berbagai macam bunga untuk dibuat poster oleh siswa. Siswa berdiskusi dan bereksplorasi secara kelompok untuk melakukan pengamatan dan pembuatan poster terkait struktur bunga.

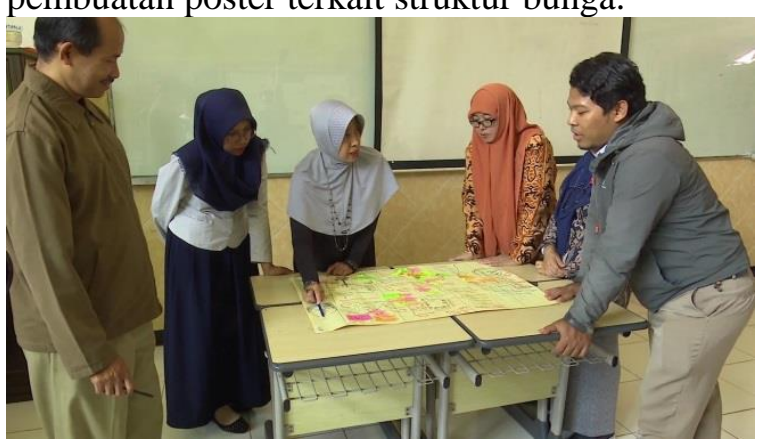

Gambar 9. Kegiatan Perencanaan Siklus II

Sebagai upaya untuk memantau pekerjaan siswa guru membuat grup whatsapp bersama semua siswa. Sehingga siswa bisa lebih mengembangkan rasa tanggung jawab mereka terhadap tugas yang harus diselesaikan. Selain itu bahan untuk penyelesaian proyek sudah disediakan oleh guru agar siswa bisa lebih maksimal memanfaatkan waktu untuk melakukan kajian dan ekplorasi materi. Siswa melakukan presentasi dan guru akan memberikan penguatan materi di akhir pertemuan.

\section{Pelaksanaan II}

Tahap ini dilakukan dalam dua pertemuan, yaitu hari Senin 13 Agustus 2018 (pertemuan pertama) dan Rabu 15 Agustus 2018 (pertemuan kedua). Apresepsi yang digunakan oleh guru adalah menampilkan strobilus pinus dan bunga sepatu. Hal ini digunakan untuk memicu perhatian siswa dan membuat mereka termotivasi. Adanya media dapat memberikan pengaruh terhadap motivasi siswa (2U Inc., 2018; Chiang \& Lee, 2016; Lai, 2011; Mahadzir \& Phung, 2013; Puspitorini et al., 2014; Williams \& Williams, 2011). Selanjutnya pada kegiatan inti, yaitu diskusi kelompok, guru membagikan 4-5 bahan untuk diamati. Hal ini menyebabkan setiap anggota kelompok mendapatkan bahan yang harus diamati (Gambar 10). Hal ini sengaja dilakukan oleh guru untuk memunculkan rasa tanggung jawab pada diri siswa, khususnya tugas dalam belajar kelompok.

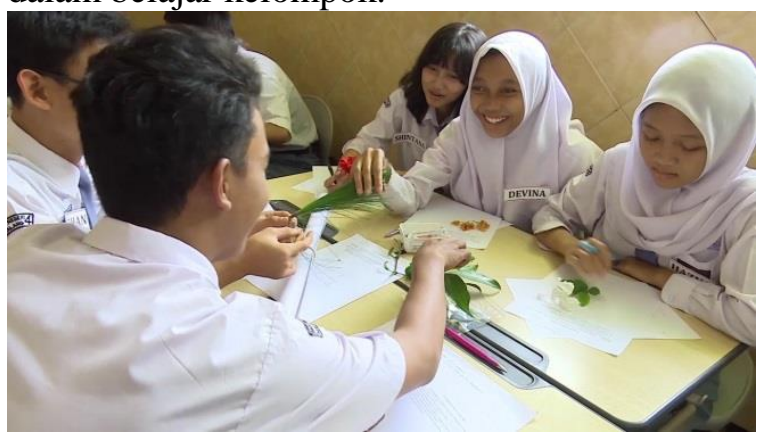

Gambar 10. Siswa Melakukan Diskusi Kelompok dengan Bahan Amatan yang Berbeda untuk Setiap Orang

Pada saat diskusi, guru juga menunjuk siswa yang sudah bisa menyelesaikan tugasnya untuk menjelaskan kepada teman dari kelompok lain dengan bahan amatan yang sama. Hal ini akan memberikan motivasi pada siswa dalam belajar. Media realia yang ada menumbuhkan motivasi dalam diri siswa untuk melakukan pengamatan dan mendukung pemahaman konsep pada mereka (Baker et al., 2011; Bell, 2010; Williams \& Williams, 2011). Setelah kegiatan diskusi selesai, siswa diberikan kesempatan untuk mempresentasikan hasil diskusinya, seperti Gambar 11.

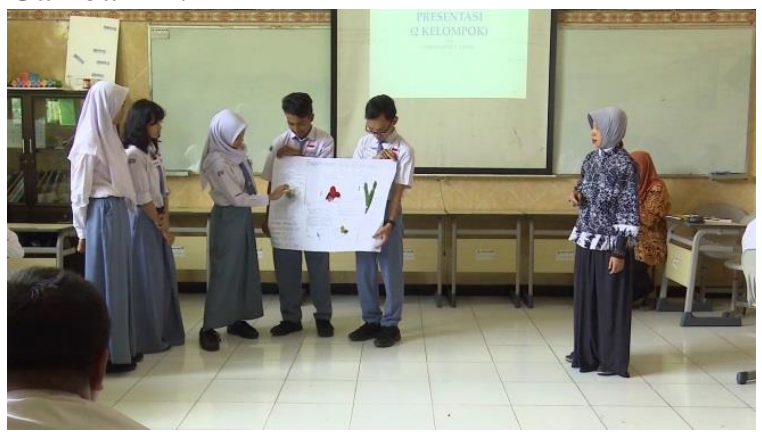

Gambar 11. Salah Satu Kelompok yang Mempresentasikan Hasil Proyek Mereka

\section{Refleksi II}

Kegiatan refleksi siklus II dilakukan pada tanggal 15 Agustus 2018 (Gambar 12). 


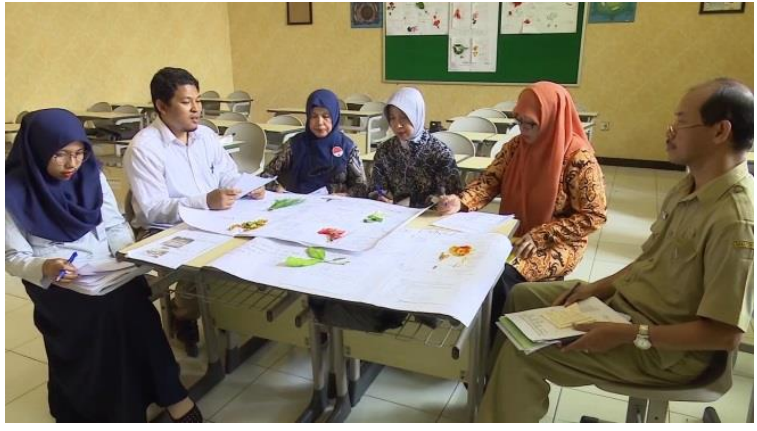

Gambar 12. Kegiatan Refleksi Siklus II

Hasil refleksi kegiatan pembelajaran yang berlangsung menunjukkan bahwa siswa sangat antusias dan termotivasi dengan pembelajaran yang didukung oleh media realia yang disediakan dalam pembelajaran. Berdasarkan hasil observasi, $88.23 \%$ dari 34 siswa yang menunjukkan motivasi mereka dalam proses pembelajaran berbasis proyek. Proyek siswa, pada siklus II ini pembuatan poster, memiliki waktu yang terbatas untuk penyelesaian proyek. Hal ini mengakomodasi siswa untuk menggunakan strategi yang paling efektif, melatih ketekunan dan memunculkan kemauan dalam belajar (2U Inc., 2018; Badia \& Soria, 2017; Bell, 2010; Ergül \& Kargın, 2014; Lin \& Wu, 2016; Turner, 1995). Sedangkan hasil kuesioner menunjukkan bahwa $85.29 \%$ dari 34 siswa yang sudah memiliki rasa tanggung jawab untuk belajar, dalam hal ini terkait dengan pengamatan bunga dan pembuatan poster. Siswa menunjukkan motivasi untuk belajar sehingga rasa tanggung jawabnya terhadap pekerjaannya juga meningkat (Lai, 2011; Williams \& Williams, 2011). Namun demikian pembelajaran berbasis proyek membutuhkan kerja keras dari guru, karena guru harus bisa melakukan pemantauan terhadap pekerjaan siswa dan harus mampu mengelola waktu dalam pembelajaran di kelas dengan optimal.

\section{SIMPULAN}

Implementasi pembelajaran berbasis proyek dapat meningkatkan motivasi dan rasa tanggung jawab pada diri siswa. Hal ini dikarenakan proyek yang harus diselesaikan dalam waktu tertentu menyebabkan siswa harus bisa mengelola waktunya yang berperan dalam melatih tanggung jawab mereka yang ditunjukkan dengan persentase sebesar $85.29 \%$ (dari 34 siswa). Selanjutnya adanya media pada penyelesaian proyek membuat siswa tertarik dan termotivasi untuk belajar yang ditunjukkan dengan nilai persentase sebesar 88.23\% (dari 34 siswa). Waktu yang terbatas untuk penyelesaian proyek mengakomodasi siswa untuk menggunakan strategi yang paling efektif, melatih ketekunan dan memunculkan kemauan dalam belajar. Namun, pembelajaran berbasis proyek membutuhkan kerja keras dari guru, terkait pemantauan terhadap pekerjaan siswa dan pengelolaan waktu dalam pembelajaran di dalam kelas.

\section{DAFTAR PUSTAKA}

2U Inc. (2018). Motivating students. Retrieved from https://teach.com/what/teacherschange-lives/motivating-students/

Arce, M. E., Miguez, J. L., Granada, E., Miguez, C., \& Cacabelos, A. (2013). Project-based learning: Application to a research master subject of thermal engineering. Journal of Technology and Science Education, 3(3), 132-138. https://doi.org/10.3926/jotse.81

Aulbur, W., CJ, A., \& Bigghe, R. (2016). Skill development for Industry 4.0. India: Roland Berger.

Badia, J. D., \& Soria, V. M. (2017). Creative project-based learning to boost technology innovation. Revista D'innovació Educativa, (18), 1-13. https://doi.org/10.7203/attic.18.9019

Baker, E., Trygg, B., Otto, P., Tudor, M., \& Ferguson, L. (2011). Project-based learning model, relevant learning for the 21 st century. Pacific Education Institute.

Bandura, A. (1991). Social cognitive theory of moral thought and action. In Handbook of Moral Behavior and Development Volume 1: Theory (pp. 45-103). Hillsdale, New Jersey: Lawrence Erlbaum Associates.

Bell, S. (2010). Project-based learning for the 21st century: Skills for the future. The Clearing House: A Journal of Educational Strategies, Issues and Ideas, 83(2), 39-43. https://doi.org/10.1080/000986509035054 15

Chiang, C. L., \& Lee, H. (2016). The effect of project-based learning on learning motivation and problem-solving ability of vocational high school students. International Journal of Information and Education Technology, 6(9), 709-712. https://doi.org/10.7763/IJIET.2016.V6.77 9

Cook-Sather, A. (2010). Students as learners and teachers: Taking responsibility, transforming education, and redefining accountability. Curriculum Inquiry, 40(4), 
$555-575$.

D. Patrick Saxon. (2013). Student responsibility and self-directed learning: An interview with Christine McPhail. Journal of Development Education, 36(3), 14-17.

Dean, C. D., Hibbard, K. L., Lange, H. G., Levin, B. B., Mettetal, G., Rock, T. C., ... Shumow, L. (2001). Energizing teacher education and professional development with problem-based learning. (B. B. Levin, Ed.). Alexandria, VA: Association for Supervision and Curriculum Development.

Erb, M. (1996). Increasing students responsibility for their learning through multiple intelligence activities and cooperative learning. Saint Xavier University.

Ergül, N. R., \& Kargın, E. K. (2014). The effect of project based learning on students' science success. Procedia-Social and Behavioral Sciences, 136, 537-541. https://doi.org/10.1016/j.sbspro.2014.05.3 71

Filak, V. F., \& Sheldon, K. M. (2008). Teacher support, student motivation, student need satisfaction, and college teacher course evaluations: testing a sequential path model. Educational Psychology, 28(6), 711-724.

https://doi.org/10.1080/014434108023377 94

Gottfried, A. E. (1990). Academic intrinsic motivation in young elementary school children. Journal of Educational Psychology, 82(3), 525-538.

Hartmann, E. A., \& Bovenschulte, M. (2013). Skills needs analysis for "Industry 4.0" based on roadmaps for smart systems. In SKOLKOVO (Ed.), Using Technology Foresights for Identifying Future Skills Needs. Global Workshop Proceedings (pp. 24-36). Moscow.

Irvin, J. L., Meltzer, J., \& Dukes, M. S. (2007). Student motivation, engagement, and achievement. In Taking Action on Adolescent Llteracy: An Implementation Guide for School Leaders. Association for Supervision and Curriculum Development.

Isabekov, A., \& Sadyrova, G. (2018). Projectbased learning to develop creative abilities in students. In J. Drummer, G. Hakimov,
M. Joldoshov, T. Köhler, \& S. Udartseva (Eds.), Vocational Teacher Education in Central Asia. Technical and Vocational Education and Training: Issues, Concerns and Prospects (pp. 43-49). Springer, Cham. https://doi.org/10.1007/978-3-31973093-6_4

Jati, N. K. (2016). Meningkatkan tanggung jawab siswa menggunakan model pembelajaran kooperatif tipe jigsaw II pada mata pelajaran matematika Kelas IV SD. Jurnal Pendidikan Guru Sekolah Dasar, 34, 196210.

Lai, E. R. (2011). Motivation: A literature review. Retrieved from https://images.pearsonassessments.com/i mages/tmrs/Motivation_Review_final.pdf

Lin, C.-S., \& Wu, R. Y.-W. (2016). Effects of web-based creative thinking teaching on students' creativity and Learning Outcome. EURASIA Journal of Mathematics, Science \& Technology Education, 12(6), 1675-1684. https://doi.org/10.12973/eurasia.2016.155 $8 \mathrm{a}$

Lubis, M. A., Lampoh, A. A., Yunus, M. M., Shahar, S. N., Ishak, N. M., \& Muhamad, T. A. (2011). The use of ICT in teaching Islamic subjects in Brunei Darussalam. International Journal of Education and Information Technologies, 5(1), 79-87.

Mahadzir, N. N. N., \& Phung, L. F. (2013). The use of augmented reality pop-up book to increase motivation in English language learning for national primary. IOSR Journal of Research \& Method in Education (IOSR-JRME), 1(1), 26-38. https://doi.org/doi:10.6084/m9.figshare.11 76011

Pfeiffer, S. (2015). Effects of Industry 4.0 on vocational education and training. (I. of T. A. (ITA), Ed.). Vienna: Austrian Academy of Sciences (ÖAW).

Puspitorini, R., Prodjosantoso, A. K., Subali, B., \& Jumadi, J. (2014). Penggunaan media komik dalam pembelajaran IPA untuk meningkatkan motivasi dan hasil belajar kognitif dan afektif. Jurnal Cakrawala Pendidikan, 3(3), 413-420. https://doi.org/10.21831/CP.V3I3.2385

Ratnaningrum, D. A., Chamisijatin, L., \& Widodo, N. (2016). Penerapan pembelajaran guided inquiry untuk 
meningkatkan motivasi dan hasil belajar IPA pada siswa Kelas VIII-A SMP Muhammadiyah 2 Batu. Jurnal Pendidikan Biologi Indonesia, 1(2). https://doi.org/10.22219/JPBI.V1I2.3334

Saeed, S., \& Zyngier, D. (2012). How motivation influences student engagement: a qualitative case study. Journal of Education and Learning, 1(2), 252-267. https://doi.org/10.5539/jel.v1n2p252

Saragih, L. (2012). Pengaruh penggunaan video pembelajaran terhadap motivasi belajar siswa pada pembelajaran sistem injeksi bahan bakar diesel Kelas XI Jurusan Teknik Kendaraan Ringan SMK Piri Yogyakarta. Universitas Negeri Yogyakarta.

Schwartz, K., Tessman, D., \& Mcdonald, D. (2013). The value of relevant, projectbased learning to youth development (Vol. $8)$.

Swain, M. S. (2012). Perceived responsibility for learning in college students: A construct validity study. James Madison University.

Takeda, I. (2016). Report: Project-based learning with 21st century skills for the Japanese language classroom. Journal of Integrated Creative Studies.

Taufik, M. (2014). Penggunaan media video untuk meningkatkan motivasi dan hasil belajar siswa (studi kasus pada siswa kelas X5 SMA Muhammadiyah 3 Jember semester ganjil Tahun 2013-2014 pada mata pelajaran ekonomi). Universitas Negeri Jember.

Taurina, Z. (2015). Students' motivation and learning outcomes: Significant factors in internal study quality assurance system. International Journal for CrossDisciplinary Subjects in Education (IJCDSE), 5(4), 2625-2630.

Turner, J. C. (1995). The influence of classroom contexts on young children's motivation for literacy. Reading Research Quarterly, 30(3), 410-441. https://doi.org/10.2307/747624

Vrbik, I., \& Vrbik, A. (2017). Video Demonstration as a Teaching Method. Croatian Journal of Education, 19(2), 201-213. https://doi.org/10.15516/cje.v19i0.2674

Williams, K. C., \& Williams, C. C. (2011). Five key ingredients for improving student motivation. Research in Higher Education Journal, 11, 1-23. Retrieved from http://scholarsarchive.library.albany.edu/ math_fac_scholar

Yulistiana, W. (2010). Implementasi model pembelajaran $L C$ " $5 E$ " dengan mengoptimalkan media pembelajaran worksheet untuk meningkatkan motivasi belajar siswa pokok bahasan segiempat. Universitas Muhammadiyah Surakarta. 